\title{
Designing the simulation learning environment: An active engagement model
}

\author{
Rodney Fisher* \\ College of Health Sciences, Nurse Anesthesia Program, Midwestern University, Glendale, Arizona, United States
}

Received: September 28, 2015

DOI: $10.5430 /$ jnep.v6n3p6
Accepted: November 2, $2015 \quad$ Online Published: November 12, 2015

URL: http://dx.doi.org/10.5430/jnep.v6n3p6

\begin{abstract}
Simulation is rapidly becoming a significantly learning methodology in healthcare education. The unique characteristics of simulation learning create a bridging experience between the classroom and actual patient care and, more importantly, helps learners develop advanced clinical reasoning skills. Learner active engagement is a critical requirement for effective learning during simulation and debriefing, which tasks educators to design simulation learning environments that foster learner active engagement. To foster learner active engagement, the educator and the learner must develop a dyadic relationship of trust, openness, sharing, and safety. The formation of this dyadic relationship implies that the learner has engaged in the learning environment. The simulation literature lacks significant discussion of how the elements of the simulation learning environment can be used to create a learning environment that encourages active engagement in the learning process. From the information gathered through a literature search in CINHAHL, PubMed, and Psychology and Behavioral Sciences databases, this article describes the critical elements of effective simulation learning. The purposes of this article are to elucidate how the interaction of important elements of the simulation experience can foster active engagement and to introduce an Active Engagement Model as a framework for designing the simulation learning environment that encourages and supports learner engagement. The components of the model are the educator, the learner, the environment, which must interact effectively to form the functional entity of the model - the educator/learner dyad. Once the educator/learner dyad is formed, all the elements of the model function in concert to form an effective simulation learning environment.
\end{abstract}

Key Words: Active engagement, Simulation learning environment, Experiential learning, Learners, Educators

\section{INTRODUCTION}

To respond to societal pressures to prepare more highlyqualified graduates possessing advanced clinical reasoning skills, healthcare educators must design innovative learning environments using teaching modalities that foster learner engagement. ${ }^{[1,2]}$ One effective teaching modality is simulation learning. In contrast with the traditional classroom lecture, simulation offers an experiential learning environment in which learners engage on multiple levels: psychomotor, $\operatorname{cog}$ nitive, social, and emotional. The interactive nature of the simulation and debriefing experience fosters the development of clinical reasoning skills, ${ }^{[3]}$ psychomotor skills,,${ }^{[4]}$ learner self-efficacy ${ }^{[5]}$ and acts to bridge the transition from classroom instruction to actual patient care. This uniquely dynamic learning environment does not occur spontaneously, but must be innovatively designed by educators.

From information gathered through a literature search of the CINAHL, PubMed, and Psychology and Behavioral Sciences databases using the keywords simulation learning, active engagement, learning environments, and debriefing, this article

* Correspondence: Rodney Fisher, CRNA, MSN; Email: rfishe1@ midwestern.edu; Address: College of Health Sciences, Nurse Anesthesia Program, Midwestern University, Glendale, Arizona, United States. 
reviews the critical elements and their interactions of the simulation learning environment (SLE). A growing number of simulation researchers reported improved learning following simulation experiences. ${ }^{[6,7]}$ Other investigators proposed that more advanced cognitive processing and assimilation occurs during effective debriefing after simulation. ${ }^{[8,9]}$ Simulation, coupled with a proper debriefing experience, offers the learner a uniquely effective learning environment in which to develop clinical reasoning skills; provided it is designed and conducted in a manner which fosters learner active engagement.

Along with highlighting the importance of learner active engagement in simulation and debriefing, Dreifuerst identified defining characteristics of the debriefing process: reflection, emotion, reception, and integration and assimilation. ${ }^{[10]}$ It is most certain that these same characteristics are important during the simulation component also and must be considered in the design of the SLE. In 2005, Jeffries introduced a framework for designing simulation experiences describing the elements of the simulation experience. ${ }^{[1]}$ Over the past decade, the simulation education community has focused on identifying important components of effective simulation experiences, yet there has been inadequate discussion on how the design of the SLE fosters active engagement through the interaction of the key elements. Due to the recent growth of simulation education, many educators are unfamiliar with the important interactions of the key elements needed to create effective simulation and debriefing learning environments.

De Maria et al. proposed that increasing fidelity in the SLE fosters learning through the interaction of realistic psychological, technological, and environmental elements. ${ }^{[11]}$ These authors also suggested that the emotional component of the simulation experience facilitates learning by enhancing memory processing. In a systematic review of current simulation literature, Cook et al. found the following elements are important for simulation-based education: range of difficulty, repetitive practice, distributed practice, cognitive interactivity, multiple learning strategies, individual learning, mastery learning, feedback, longer time, and clinical variation. ${ }^{[12]}$

It is beyond the scope of this paper to discuss each of the elements described by the aforementioned authors. With this in mind, this paper discusses the main interactive elements of the simulation experience. As educators understand the important characteristics and interactions of the elements of the SLE, they will better understand how to design an environment that fosters learner active engagement and the development of advanced clinical reasoning skills. The purposes of this paper are to explore some of the important characteristics of the key elements of simulation and debriefing learning

Published by Sciedu Press and expand our understanding of the critical interactions between these elements by introducing an Active Engagement Model to be used as a framework for creating a SLE that fosters learner active engagement.

\section{SIMULATION ENVIRONMENT ELEMENTS}

\subsection{Reflection}

Reflection is a process of evaluating one's own performance, the decisions made, and the cognitive processes that underlie those decisions. ${ }^{[13]}$ Borrowing concepts used by the military and the aviation industry, healthcare educational practices now incorporate debriefing in simulation experiences to enhance deeper learning and develop clinical reasoning skills. ${ }^{[14]}$ Reflection can occur throughout the simulation experience, but is a crucial element of the debriefing component. The adult learning theory emphasizes a unique conceptual framework that supports deeper learning using simulation technology and reflection. ${ }^{[15]}$ When combined with facilitated reflection, learning through effective simulation and debriefing reflects an experiential learning process, which is a key factor in adult learning. ${ }^{[16]}$ Many authors in the simulation literature promoted reflection as a significant component of the debriefing process. ${ }^{[1,9,14,17]}$

Learners may initiate self-reflection during the simulation experience or be guided through the reflective process by the educator. As mentioned above, reflection can occur before, during and after the actual simulation, but is most effective during the debriefing experience when the learner is not cognitively and emotionally occupied with decision-making and personal performance tasks occurring during the simulation component. Through guided reflection, learners revisit the simulation experience and review performance of psychomotor skills and decision-making processes. If the decisions were correct, then the decision-making processes are reinforced. If the decisions were inappropriate, the educator can guide learners in evaluating and modifying, not just their decisions, but also their decision-making processes. Through this reflective process, the learner enhances clinical reasoning skills. Jeffries suggested that a properly designed simulation experience with an adequate reflection component is one of several valuable tools for the educator to help prepare competent healthcare professionals for practice in the workplace. ${ }^{[1]}$ This experiential learning process is the foundation of simulation and debriefing. Learning how to effectively guide the reflection process is challenging for many educators, especially those new to this emerging technology. Cheng et al. proposed that educators should have structured opportunities to develop, maintain and enhance skills in effective simulation and debriefing techniques. ${ }^{[18]}$ 


\subsection{Emotion and stress}

Clapper described learning as an emotional event. ${ }^{[15]}$ This is especially true for the simulation experience. Effective educational environments allow learners to enhance the understanding of their surroundings and develop decision-making skills through experience. Beyond providing knowledge and context, life and educational experiences provide social and emotional development. Emotion is created by the learner's perception of an experience and is a significant characteristic of both the simulation and debriefing experiences. Emotional perception is a multi-factorial process resulting from the $\operatorname{cog}$ nitive processing of many elements: multiple sensory inputs, cultural background, psychosocial development, trait anxiety (TA), and past experiences. As a result, educators may not be completely aware of what the learner is perceiving. A perception of an exciting and safe environment fosters learner engagement. If the learner perceives a threatening environment, he or she may disengage from the experience. Positive and negative emotions associated with the learning environment determine learner engagement and can impact the learning process.

The perception of a threatening environment causes an anxiety or stress reaction in the learner. Derakshan defined this anxiety reaction as an "aversive motivational state" in which the learner engages in avoidance or defensive behaviors. ${ }^{[19]}$ An aversive motivational state may lead the learner to disengage from at least a portion of the learning experience. A challenge for the educator is to identify perceived threats or subsequent avoidance or defensive behaviors before the learner disengages from the experience.

Both the perception of a threat and the body's physiologic response to anxiety affect cognitive processing in multiple brain areas during memory encoding, consolidation and retrieval. ${ }^{[11,20,21]}$ Many people have experienced forgetting a well-known fact during a stressful event, only to remember it later in a more relaxed environment. One possible explanation for this "forgetful episode" is the result of the release of the stress-response chemicals epinephrine and glucocorticoids. In the amygdala, epinephrine and glucocorticoids enhance emotional learning and memory consolidation, ${ }^{[22]}$ but impair retrieval of memories if the stress occurs at the time of the retrieval attempt. ${ }^{[23]}$ This memory retrieval impairment may be one of the causes of test anxiety. Miu, Heilman, and Houser found alterations in decision-making depending on the level of TA (individual's sensitivity to the perception of threat) of the learner. ${ }^{[24]}$ These researchers found impaired decision-making and more profound anticipatory stress responses in subjects with high TA. Calvo, Avero, and Miguel-Tobal discovered that high TA adversely affects attentional memory and leads to preferential processing of threat stimuli. ${ }^{[25]}$ Additionally, research showed impaired recollection of extrinsic (contextual) details of an emotional experience. ${ }^{[26]}$ This research suggests that the learner may remember a stressful simulation experience but may have performed poorly as the result of impaired attention and impaired retrieval of important facts required to make correct decisions.

Other neurophysiological research shows emotion and stress to be important factors in task management during cognitive processing. ${ }^{[27]}$ Edwards, Edwards, and Lyvers found that stress and anxiety adversely affect task performance, impairing the learner's ability to shift attention during the learning experience. ${ }^{[28]}$ Attention shifting is a common feature unique to the simulation environment. During simulation, the learner's attention constantly shifts between several foci: decision-making, performing psychomotor skills, monitoring effects of the decisions, directing the actions of other participants, and listening to and responding to educator feedback. These actions often occur rapidly and are cognitively intensive. Responding to a perceived threat during the simulation may cause the learner to dedicate important central cognitive functions to deal with the threat (a higher-priority event), leaving other tasks suspended. In this event, task performance and decision-making processes suffer, which may lead to poor performance and learning outcomes. Educators designing learning environments should incorporate methods to identify and modulate emotion and stress in an effort to optimize learning and keep the learner engaged. ${ }^{[29,30]}$

Rudolph et al. described the effects of using judgmental and non-judgmental approaches in the debriefing process. ${ }^{[13]}$ These authors suggested that learners may suffer significant emotional harm if improper debriefing techniques are used. Zigmont, Kappus, and Sudikoff indicated that learners are less likely to talk openly if they perceive a judgmental environment. ${ }^{[31]}$ A judgmental environment may hinder all aspects of the simulation experience, especially the reflective process. If learners perceive that they are being blamed for a failed simulation scenario or thwarted the group's effort during simulation, they may experience feelings of humiliation. This may also lead to a reluctance to engage in the debriefing process and future simulation experiences. Educators creating simulation learning experiences should be aware of the adverse effects of a judgmental environment on emotion and monitor the learner and the group dynamics throughout the entire simulation experience.

Zigmont et al. proposed that the debriefing process should begin with a "defusing" experience. Defusing allows learners to discuss the emotional impact of the simulation experience. ${ }^{[31]}$ Unless the simulation is evaluative, learners should 
be instructed that the simulation is a learning experience and that poor scenario outcomes are a part of the learning process. Entering into the reexamination phase of debriefing without resolving the emotional impact of the simulation may prevent learners from focusing on their decision-making processes. Learners may be so frustrated with the outcome of the scenario that they are unable to "learn from their mistakes". Once learners can vent emotions, they will look more objectively at their decision-making processes, which is a critical step in developing clinical reasoning skills. As students vent their emotions, educators can identify elements of the simulation experience that were potentially harmful. This information will improve future simulation design.

\subsection{Reception}

Reception refers to a learner's willingness to receive feedback during the simulation experience and most often occurs during the reflection component of debriefing. This "openness", as described by Dreifuerst, is related to learner engagement and may need to be taught to the student. ${ }^{[10]}$ Adult learners re-entering the educational environment may be unfamiliar with constructive feedback and the reflective process. It is unlikely that today's adult learners have been sufficiently exposed to many of the important cognitive activities unique to the simulation experience. Within the last several decades, there has been a growing effort to incorporate the theories and methodologies of adult learning and cognition into higher education which support the use of reflection and feedback in education.

If learners are comfortable with the reflective process, they will be more willing to receive feedback on their actions. In simulation and debriefing, learners engage in cognitive, affective, and psychomotor components. Feedback on each of these components can come from the educator or peers who are participating in the simulation scenario. Kuiper et al. suggested that by receiving feedback on all components of the simulation experience, reflective learners can visualize and incorporate "affective and behavioral learning" processes required for deeper learning. ${ }^{[32]}$ All participants should be instructed that feedback should be presented in a nonthreatening, positive manner to prevent emotional harm. Learners who are aware that feedback will be positive and constructive should feel comfortable in accepting the critique of their efforts and using it to promote learning.

\subsection{Learning through integration and assimilation}

Integration refers to incorporating newly acquired knowledge into existing cognitive frameworks. ${ }^{[10]}$ New learning is best retained if it is incorporated into an existing framework of previously learned knowledge. Learners commonly come to the simulation experience with an existing cognitive framework to which more knowledge and experience can be added. It is the educator's responsibility to show learners the relationship of the new knowledge to what the learner should already possess. If new knowledge does not fit into the learner's existing framework, the old framework may have to be "torn down" to construct new framework. Learners who have been out of the educational process for some time may have old, incomplete, or outdated frameworks that no longer agree with or support new knowledge. Through the process of facilitated reflection, learners are guided to recognize the liability of the "old" frameworks and assisted in replacing them with "up-to-date" frameworks upon which the new knowledge may be attached. Other learners may come to the simulation with an incomplete framework that will not support additional new knowledge. In this case, the educator may have to guide the learner to "strengthen" existing frameworks. This may be accomplished either by pre-simulation assignments, sending the learner out from the simulation to "read the text", or by filling in the knowledge deficits during the simulation and/or debriefing. It is important that during the development of the simulation scenario the educator take into account the knowledge that learners currently possess. Expecting the learner to make decisions based on knowledge not previously acquired will lead to frustration and anxiety.

Assimilation is the ultimate goal of simulation and should be the ultimate goal of all educational enterprise. ${ }^{[10]}$ Assimilation refers to the application of past learning to future experiences. All learners should be able to use the knowledge gained in their education in future experiences. Assimilation may be assessed by asking thought-provoking (Socratic) questions to determine if learners are using the new knowledge. Future simulation scenarios will also measure assimilation.

\section{THE ACTIVE ENGAGEMENT MODEL}

Designing the SLE involves much more than compiling the important elements of simulation and debriefing experiences. Innovative educators design learning environments that encourage active engagement in the learning process. Engagement refers to more than just physical participation in the simulation and requires significant time to develop properly. Active engagement creates a personal connection with the learning experience and motivates the learner to take greater responsibility in the learning process. Instead of the educator controlling all aspects of the learning, the learner "reaches out" to make personal connections with all parts of the learning environment and helps to ensure proper functioning of the entire "system". This process of active engagement should 
begin early in the educational experience and must certainly be well-developed before entering the simulation learning environment.

Experiential learning through simulation has the characteristic of attaching emotion to the experience through realism. This is especially apparent as simulation fidelity and complexity increase. Learners apply previously learned knowledge, skills, and attitudes in making critical decisions while interacting with a simulated patient and other participants. The simulator responds in real-time providing realistic feedback. The learner's decisions have an immediate impact on themselves, the simulated patient, and other participants joining the simulation. Effective simulation is often challenging, adding to the emotional aspect of the experience. The post-simulation debriefing process enhances learning and development of clinical reasoning skills by reexamining the events, reflecting upon the emotions elicited, analyzing the mechanisms of decision-making, and reviewing the decisions made and the outcomes of the scenario. Reflection should elucidate ineffective decision-making processes and lead participants to discover more appropriate reasoning processes for use in future simulated or real-life experiences.

As mentioned above, the process of learner active engagement does not occur spontaneously in many educational environments. Even before learners enter the simulation environment, innovative educators should design multiple learning environments where active engagement can be learned and fostered. Although classroom and simulation learning environments are dissimilar in many aspects, the design characteristics of both environments that foster active engagement follow similar basic principles. The following is a proposed model, developed by the author, to examine the key interactive elements of the SLE that foster learner active engagement. The model consists of four major interactive components - The educator, the learner, the environment, and the educator/learner dyad (see Figure 1). Effective learning does not occur with each of these components acting independently. As will be discussed below, the educator, the learner, and the environment have unique characteristics that determine learner engagement in the experience. If the learner engages, the educator/learner dyad is formed, which becomes the functional component of the model.

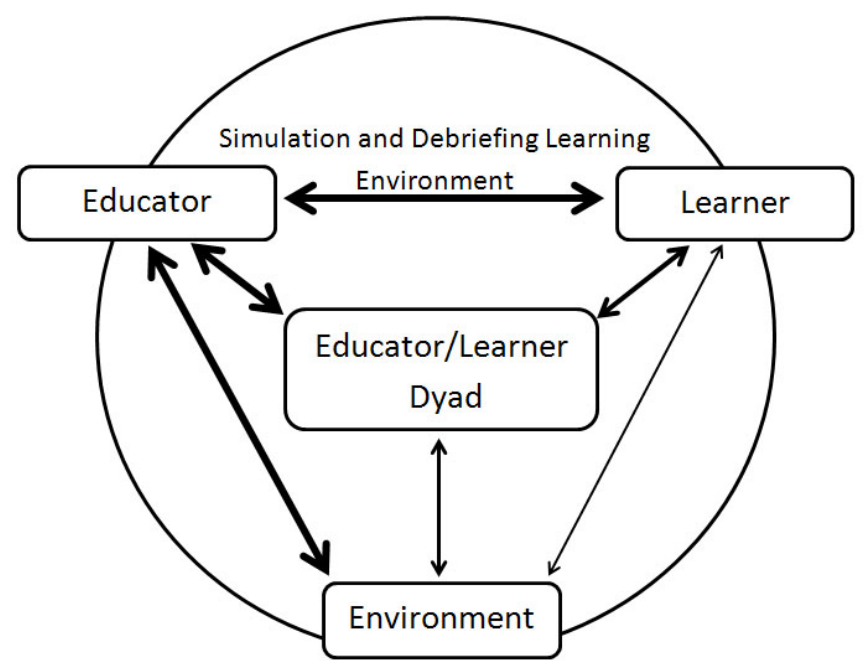

Figure 1. Active Engagement Model for the simulation and debriefing environment

The educator, learner, and the environment are interrelated components that impact the creation of the educator/learner dyad, which is the functional entity of the simulation and debriefing learning environment. Heavier weighted arrows associated with the educator indicate greater influence on the learner and environment components and on the creation of the educator/learner dyad.

\subsection{The educator}

The educator is responsible for designing and managing an effective SLE. During simulation, the educator guides learners through multiple learning experiences: pre-simulation preparation, the actual simulation scenario, and debriefing. Educators bring knowledge, expertise, expert clinical reasoning skills, and maturity to the environment. Other important characteristics required for this model are patience, humility, empathy, creativity, vision, familiarity with the technology, a solid understanding of adult learning theory, and effective debriefing skills. These characteristics and skills are required to design and conduct simulation experiences that encourage learner engagement. Although the educator is critical to the design and management of the environment, it is the learner who must ultimately engage in the experience to develop the facilitator/learner dyad. The development of the 
educator/learner dyad is critical for effective learning and demonstrates that the learner has actively engaged.

The most important outcome of simulation is to develop clinical reasoning skills. Learners develop these skills by engaging in learning experiences where they are required to make critical decisions. Afterward, they need an opportunity to review the decision-making process to determine its effectiveness. Most learners have difficulty identifying improper decision-making processes using newly acquired knowledge. It is usually easy to point out incorrect actions, but it can be challenging for educators to help learners identify faulty decision-making processes. The reflection process is the most effective method to get learners to visualize their decision-making processes and learn from them. During reflection, an effective educator facilitates the learner's visualization of the decision-making processes used and assists the learner to modify those processes if needed. Facilitating the visualization of both proper and improper decision-making processes is critical for the learner and the educator can only develop this skill through experience.

With the growth of diversity within our educational system, educators may not recognize subtle personal biases. If learners sense a bias in the educator, they may perceive the environment as threatening. This may lead to diminished respect for the educator and prevent engagement; impairing the creation of the critical educator/learner dyad. Educators must be sufficiently humble to be aware of personal biases and be willing to eliminate them. This effort will foster more effective communication with learners, develop trust, and provide a safe learning environment. Simulation learning frequently involves adult learners with unique learning needs and abilities. Educators should also be familiar with how a diverse group of adults learn more effectively and incorporate those principles into the design of the SLE.

The educator must also be aware of the many factors that can cause learner stress and anxiety. During simulation and debriefing, it is very important that the educator monitor the level of anxiety. A distinction should be made between a challenging experience and one that is emotionally harmful. These two types of environments fall next to each other on the continuum of educational environments and there may be a fine line separating the two types. Some situational stress is highly beneficial in simulation education. Stressful experiences can prepare the learner for making critical decisions in the real world. The educator should be able to recognize if the anxiety level crosses the boundary into a threatening environment and quickly defuse the situation, preferably without disrupting the learning experience if at all possible. Sometimes it may be necessary to prematurely stop

Published by Sciedu Press the simulation and begin a facilitated debriefing experience if the anxiety level is inhibiting the learning process. An awareness of the adverse effects of high-anxiety on learning will encourage the educator to more carefully monitor the environment for signs of stress and anxiety.

High-fidelity mannequins are extremely complex computerdriven systems, which require training and experience to run simulation scenarios effectively. Some systems have pre-programmed scenarios and some systems have to be programmed. Most of the mannequins allow for manipulation of physiologic parameters to create realism (fidelity). The simulation educator can also increase fidelity by designing realistic scenarios and physical environments. The educator must be thoroughly familiar with the simulation technology before engaging in SLE design. An educator struggling to manage an unfamiliar simulator will not be focusing on the learning processes and will find great difficulty getting the student to engage in the learning.

Many of these educator characteristics develop with time and experience. Both the educator and the learner benefit from interactions developed with frequent simulation experiences. The educator develops a greater understanding of the learner's decision-making skills and can assist to enhance those skills. The learner benefits from multiple opportunities to interact with the educator and to practice decision-making skills. It may be advisable to begin initial simulations with simple scenarios where just a few critical decisions have to be made and gradually escalate scenario complexity as the learner becomes more experienced and gains greater decision-making self-efficacy. The educator can use a gradual escalation process to assist students with high TA to develop greater self-efficacy in preparation for more challenging scenarios and testing experiences in the future.

\subsection{The learner}

Unlike the classic classroom environment, the learner in the SLE performs skills and makes critical decisions that impact scenario outcomes in front of others; which may cause psychological harm. Learners come to the SLE with varying levels of psychomotor skill development and decision-making abilities. A learner with less-developed skills may have to perform in front of the educator and peers with perceived higher-level skills. This creates a potentially stressful experience, especially in learners with high TA. Additionally, the principle of active engagement requires that some of the normal educator/learner psychosocial boundaries to be temporarily removed, which may expose the learner to the harmful effects of an unsafe or biased environment. The learner must be taught and clearly understand that the simulation is a learning experience where mistakes occur frequently 
and are a part of the learning process.

Through past educational and life experiences, learners develop unique cognitive frameworks to assist in understanding their environment and to help in decision-making. If the outcomes of those decisions are positive, those decisionmaking processes are strengthened and embedded into the learner's vast cognitive frameworks. Learners develop clinical reasoning skills by repetitively accessing these advanced cognitive frameworks during simulation experiences. Active engagement during guided reflection enhances access, proper utilization, modification, and consolidation of these advanced cognitive frameworks.

The ability to engage in self-reflection varies among adult learners. ${ }^{[13]}$ Schön described some professionals as having the ability to self-correct their professional skills by selfscrutiny while others tend to ignore other's perceptions about their ineffective practice habits. ${ }^{[33]}$ The learner who lacks self-scrutiny skills and ignores the perceptions of others will have poor self-corrective skills. An educator may not know if a learner has effective self-reflective skills until a debriefing session. Decker et al. proposed that self-reflective skills must be taught and modeled so that learners are comfortable with the reflective process and are willing to critically look at their decision-making skills. ${ }^{[34]}$ The educator should teach, guide, and encourage this reflective process throughout the entire educational program, but learners must be willing to engage in the learning experience. The engaged learner develops a greater sense of personal responsibility for the learning process, a greater awareness of decision-making errors, and will commit greater effort to correct the errors.

\subsection{The environment}

A safe environment for all participants is one of the most important design factors of the SLE. Rudolph et al. proposed that the environment should be challenging, but psychologically safe. ${ }^{[13]}$ The educator and peers participating in the simulation will share critical judgments with the learner. Learners must believe that these judgments are unbiased and that they are offered to improve learning and develop clinical reasoning skills. There should be a sense of trust, ensuring that all that may be revealed about the learner will be kept confidential. The educator must assure that measures are taken to monitor the environment, maintain confidentiality, and decrease the chance of a threat.

Educators should also understand the difference between a challenging environment and one that is perceived as threatening. A challenging environment is one where the learner has multiple opportunities to make critical decisions. A threatening environment is one where the learner is afraid to make critical decisions or feels humiliated and is less likely to foster clinical reasoning skills or any kind of meaningful learning. The design and conduct of the simulation will create either a challenging or a threatening environment. The educator is ultimately responsible for managing the simulation environment and should make sure rules regarding appropriate interaction are well known by all the participants prior to the experience.

If educators primarily use lecture in the classroom, learners may be unfamiliar with the reflective process or engagement in the learning environment. Teacher-centered education (lecturing) is a passive process and does not encourage active engagement. Learner-centered education fosters active engagement. ${ }^{[35]}$ The simulation learning experience proposed in this model is an excellent example of learner-centered education. Another effective methodology that fosters engagement is a team-based approach, where small groups act as a team to accomplish a specific simulation scenario. Sisk found that team-based learning experiences are a promising method for engaging students and fostering productive teamwork. ${ }^{[36]}$ Educators should be familiar with active or learner-centered methodologies and incorporate them into the design of the SLE to motivate students to engage in their own learning.

\subsection{The educator/learner dyad}

Effective learning depends on critical interactions between educators and learners. ${ }^{[1]}$ Although the design of an effective SLE rests on the educator, the educator/learner dyad is the main component maintaining the environment and supporting the other elements. Without engagement of the learner, the dyad is difficult to create. As discussed above, there are many factors that affect this educator/learner dyad. Due to the evolution of modern pedagogical principles, educators must become more aware of and protect learners from physical as well as psychological harm in all learning environments. If learners sense value, respect, and safety in the environment, they will freely engage and help to create and maintain the educator/learner dyad. Any perception that this relationship might not be safe to any one of the participants, including the educator, may be devastating to the learning process and may even result in harmful and long-lasting emotional effects.

A feeling of trust must also be cultivated between the learner and the educator and is essential for the development of the educator/learner dyad. Clinical reasoning skills are developed during debriefing when the learner and the educator cooperatively reexamine the simulation experience. Both explore the emotions, the decisions, and the outcomes during the reflection process. During reflection, the learner 
often has to express sensitive thoughts and feelings which may expose him or her to the harmful effects of an uncaring educator. The educator helps learners identify correct and incorrect decision-making processes through facilitated reflection, and together analyze the impact of those decisions on the outcomes of the simulation. The educator encourages learners to express their feelings along with the rationale for the decisions made. Ultimately, the learner and the educator collaborate to strengthen decision-making processes and incorporate them into the learners' cognitive frameworks for future access and decision-making. There must be open relationship between learners and the educator, including a desire to freely communicate knowledge and feelings. Reciprocal trust is essential for all these activities.

All participants should recognize the value of each other, which requires empathy and humility. Empathy is the ability to acknowledge and understand the thoughts and feelings of another person (learner). Some educators may believe the simulation environment is safe and may dismiss a learner's perception of threat. This lack of empathy will jeopardize the learning experience. Humility is an understanding that we have the same value as each other and that we all can learn from each other. The educational experience is the sharing of knowledge, skills, and attitudes. The haughty educator, who feels that learners will never attain to his or her academic level, will never be able to correct misperceptions of the learner. Learners may feel there is no value in listening to an overbearing and self-important educator. In such cases, it is extremely unlikely that any learning will occur. In another example, an educator may perceive that a learner is disengaged or disinterested and find it difficult to commit the "energy" to engage the learner. Even if the learner makes subsequent attempts to engage, the educator may dismiss it as a feigned attempt to re-engage and leave the learner on the "outside" of the learning experience looking in. A trusting and reciprocal relationship between the educator and learner is crucial for learner engagement and the development of the educator/learner dyad in the SLE.

\section{Conclusions}

Simulation learning is an effective learning experience that allows learners to develop and refine clinical reasoning skills.
Preparation of the learner, the educator, and the environment to effectively utilize the simulation and debriefing process requires active engagement. This article introduces an Active Engagement Model to expand our understanding of the interactive nature of the "main players" of the SLE by describing the characteristics and responsibilities of each model component: the educator, the learner, the environment, and the educator/learner dyad. Each is a critical component to foster active engagement of learners. The educator designs an SLE that encourages student engagement and then facilitates the creation of the educator/learner dyad. Learners bring lifeexperiences, new knowledge, and uncertainty to the learning environment. They must be motivated and willing to engage completely in the learning process through a "reflective self-discovery" in order to recognize weaknesses in decisionmaking and clinical reasoning skills and to be humble enough to correct those weaknesses with the guidance of the educator. The environment must be safe and protective of learners who are required to "unveil" themselves in order to access cognitive processes and emotions linked to decisions and actions. This unique environment must be created by educators early in the educational experience. The educator/learner dyad is the functional component of the active engagement model and refers to a safe, trusting and open interaction between the learner and the educator in order to access shared knowledge, understanding, experience, and clinical reasoning processes. This dyadic relationship can either fail to form or become unstable if one of the members fails to engage or if the environment becomes unsafe.

Simulation and debriefing is an effective adjunct to add to the educator's armamentarium. Designing the SLE is complex and challenging for the simulation educator. Learners must actively engage in the experience for deep learning and clinical reasoning to develop. All educational experiences should teach, support, and encourage active engagement from the first day of classes. Educators who want to develop clinical reasoning skills in their graduates will innovatively design engaging learning environments that utilize the effective learning experience of simulation and debriefing.

\section{Conflicts of Interest Disclosure}

The author declares that I have no competing interests.

\section{REFERENCES}

[1] Jeffries PR. A Framework for Designing, Implementing, and Evaluating Simulations Used as Teaching Strategies in Nursing. Nurs Educ Perspect. 2005; 26(2): 96-103. PMid:15921126

[2] Najjar RH, Lyman B, Miehl N. Nursing students' experiences with high-fidelity simulation. International Journal of Nursing Educa- tion and Scholarship. 2015; 12(1): 1-9. PMid:25803087 http: //dx.doi.org/10.1515/ijnes-2015-0010

[3] Jensen R. Clinical reasoning during simulation: Comparison of student and faculty ratings. Nurse Education in Practice. 2013; 13(1): 23-8. PMid:22836097 http://dx.doi .org/10.1016/j.n epr.2012.07.001 
[4] Aqel AA, Ahmad MM. High-fidelity simulation effects on CPR knowledge, skills, acquisition, and retention in nursing students: HFS and CPR knowledge and skills. Worldviews on Evidence-Based Nursing. 2014; 11(6): 394-400. PMid:25213578 http://dx.doi .org/10.1111/wvn.12063

[5] Dunn KE, Osborne C, Link HJ. High-fidelity simulation and nursing student self-efficacy: Does training help the little engines know they can? Nursing Education Perspectives. 2014; 35(6): 403-4 http://dx.doi.org/10.5480/12-1041.1

[6] Decker S, Sportsman S, Puetz L, et al. The evolution of simulation and its contribution to competency. Journal of Continuing Education in Nursing. 2008; 39(2): 74-80. http://dx.doi.org/10.3928/0 0220124-20080201-06

[7] Hayden J, Smiley R, Alexander M, et al. Supplement: The NCSBN national simulation study: A longitudinal, randomized, controlled study replacing clinical hours with simulation in prelicensure nursing education. Journal of Nursing Regulation. 2014; 5(2): C1-S64.

[8] Childs JC, Sepples S, Chambers K. Designing simulations for nursing education. In P. R. Jeffries (Ed.), Simulations in Nursing Education from Conceptualization to Evaluation. New York, NY; NLN; 2007. 40p.

[9] Shinnick MA, Woo M, Horwich TB, et al. Debriefing: The Most Important Component in Simulation? Clinical Simulation in Nursing. 2011; 7(3): e105-e11. http://dx.doi.org/10.1016/j.ecn s. 2010.11 .005

[10] Dreifuerst KT. The Essentials of Debriefing in Simulation Learning: A Concept Analysis. Nursing Education Perspectives. 2009; 30(2): 109-14. PMid: 19476076

[11] DeMaria JS, Bryson EO, Mooney TJ, et al. Adding emotional stressors to training in simulated cardiopulmonary areest enhances participant performance. Medical Education. 2010; 44: 1006-15. PMid:20880370 http://dx.doi.org/10.1111/j.1365-2923. 2010.03775.x

[12] Cook DA, Hamstra SJ, Brydges R, et al. Comparative effectiveness of instructional design features in simulation-based education: Systematic review and meta-analysis. Medical Teacher. 2013; 35: e844e75. PMid:22938677 http://dx .doi .org/10.3109/0142159X. 2012.714886

[13] Rudolph J, Simon R, Rivard P, et al. Debriefing with Good Judgment: Combining Rigorous Feedback with Genuine Inquiry. Anesthesiology Clinics. 2007; 25: 361-76. PMid:17574196 http://dx.doi.o $\mathrm{rg} / 10.1016 / \mathrm{j}$.anclin.2007.03.007

[14] Lusk JM, Fater K. Postsimulation debriefing to maximize clinical judgment development. Nurse Educ. 2013; 38(1): 16 19. PMid:23222625 http://dx.doi.org/10.1097/NNE.0b013 e318276df8b

[15] Clapper TC. Beyond Knowles: What Those Conducting Simulation Need to Know About Adult Learning Theory. Clinical Simulation in Nursing. 2010; 6(1): e7-e14. http://dx.doi.org/10.1016/j.e cns. 2009.07.003

[16] Raemer D, Anderson M, Cheng A, et al. Research regarding debriefing as part of the learning process. Simul Healthc. 2011; (6 Suppl): S52-7. PMid:21817862 http://dx.doi.org/10.1097/SIH. Ob0 $13 \mathrm{e} 31822724 \mathrm{~d} 0$

[17] Cheng A, Eppich W, Grant V, et al. Debriefing for technologyenhanced simulation: A systematic review and meta-analysis. Medical Teacher. 2014; 48: 657-66. http://dx.doi.org/10.1111/m edu. 12432

[18] Cheng A, Grant V, Diechmann P, et al. Faculty development for simulation programs: Five issues for the future of debriefing train- ing. Simulation in Healthcare. 2015; 10(4): 217-22. PMid:26098492 http://dx.doi.org/10.1097/SIH.0000000000000090

[19] Derakshan N, Eysenck MW. Anxiety, processing efficiency, and cognitive performance: New developments from attentional control theory. European Psychologist. 2009; 14(2): 168-76. http: //dx.doi.org/10.1027/1016-9040.14.2.168

[20] Talmi D, McGarry LM. Accounting for immediate emotional memory enhancement. Journal of Memory and Language. 2012; 66(1): 93-108. http://dx.doi.org/10.1016/j.jml.2011.07.009

[21] Yonelinas AP, Ritchey M. The slow forgetting of emotional episodic memories: An emotional binding account. Trends in Cognitive Sciences. 2015 May; 19(5): 259-67. PMid:25836045 http://dx.doi .org/10.1016/j.tics. 2015.02.009

[22] Rau V, Fanselow MS. Exposure to a stressor produces a long lasting enhancement of fear learning in rats. Stress. 2009; 12: 289-313. http://dx.doi.org/10.1080/10253890802137320

[23] Roozendaal B, McGaugh JL. Memory modulation. Behavioral Neuroscience. 2011; 125: 797-824. PMid:22122145 http://dx.doi.o $\mathrm{rg} / 10.1037 / \mathrm{a} 0026187$

[24] Mui AC, Heilman RM, Houser D. Anxiety impairs decision-making: Psychological evidence from an Iowa Gambling Task. Biological psychology. 2008; 77: 353-58. PMid:18191013 http://dx.doi.o rg/10.1016/j.biopsycho.2007.11.010

[25] Calvo MG, Avero P, Miguel-Tobal JJ. Multidimensional anxiety and content-specificity effects in preferential processing of threat. European Psychology. 2003; 8(4): 252-65. http://dx.doi.org/10. 1027//1016-9040.8.4.252

[26] Mao X, You Y, Li W, et al. Emotion impairs extrinsic source memory: Am ERP study. Biological Psychology. 2015. http://dx.doi.org /10.1016/j.biopsycho.2015.07.005

[27] Sousa DA. How the brain learns. 4th Edition. Thousand Oaks, CA: Corwin; 2011. 47p.

[28] Edwards EJ, Edwards MS, Lyvers M. Cognitive trait anxiety, situational stress, and mental effort predict shifting efficiency: Implications for attentional control theory. Emotion. 2015; 15(3): 350-59. http://dx.doi.org/10.1037/emo0000051

[29] Kromann CB, Jensen ML, Ringsted C. Stress and learning. Medical Education. 2010; 44: 950-52. http://dx.doi.org/10.1111/j.1 365-2923.2010.03817.x

[30] Nielsen B, Harder N. Causes of student anxiety during simulation: What the literature says. Clinical Simulation in Nursing. 2013 Nov; 9(11): e507-e12. http://dx.doi.org/10.1016/j.ecns. 2013 .03 .003

[31] Zigmont JJ, Kappus LJ, Sudikoff SN. The 3D model of debriefing: Defusing, discovering, and deepening. Semin Perinatol. 2011; 35(2): 52-8. PMid:21440811 http://dx.doi.org/10.1053/j.s emperi.2011.01.003

[32] Kuiper R, Heinrich C, Matthias A, et al. Debriefing with the OPT model of clinical reasoning during high fidelity patient simulation. Int J Nurs Educ Scholarsh. 2008; 5: Article 17.

[33] Schön D. Educating the reflective practitioner: Toward a new design for teaching and learning in the professions. San Fransisco, CA: Jossey-Bass; 1987. 174p.

[34] Decker S, Sideras S, Rockstraw L, et al. Standards of Best Practice: Simulation, Standard VI: The Debriefing Process. Clinical Simulation in Nursing. 2013; 9: e26-e29.

[35] Doyle T. Learner-Centered Teaching: Putting the Research on Learning Into Practice. Sterling, Virginia: Stylus Publishing, LLC; 2011.

[36] Sisk RJ. Team-Based Learning: Systematic Research Review. Journal of Nursing Education. 2011; 50(12): 665-69. http://dx.doi .org/10.3928/01484834-20111017-01 